\title{
Propofol-induced acute toxic hepatitis after brief sedation for endoscopic retrograde cholangiopancreatography
}

Endoscopic retrograde cholangiopancreatography (ERCP) is currently one of the most important tools for diagnosis and treatment of pancreatic and biliary diseases. Propofol is increasingly used for safe sedation in ERCP $[1,2]$. Despite its demonstrated safety, propofol has been associated with cases of severe side effects such as pancreatitis [3] or hepatitis [4].

A 66-year-old man diagnosed 2 months previously with biliary pancreatitis with residual choledocholithiasis, had recently undergone a therapeutic ERCP under brief sedation with propofol. At 48 hours after ERCP, he was admitted because of an acute condition with abdominal pain, nausea, vomiting, and increasing liver enzyme levels. Abdominal ultrasound and computed tomography (CT) showed normal findings. Blood analysis revealed an increase to 50 times the reference value for aspartate aminotransferase (AST) and alanine aminotransferase (ALT), with a slight increase in gamma-glutamyltranferase (GGT) and alkaline phosphatase, and a total bilirubin of $8.9 \mathrm{mg} / \mathrm{dl}$ (normal range $0.2-1 \mathrm{mg} / \mathrm{dl}$ ) with excess of conjugated bilirubin. Serum amylase was normal. An in-depth investigation ruled out other causes of acute hepatitis. The patient did not want to undergo liver biopsy. He was treated with supportive meas- ures, vitamin $\mathrm{K}$, and cholestyramine. In the 2 months' follow-up, the patient was asymptomatic and the liver enzymes were normal.

Propofol is a hypnotic agent that has been widely used since its approval in 1989 [3], and is actually the agent of choice in several ambulatory surgical procedures. It has been as effective as other sedative agents, with lesser side effects [1,2], and has been shown to provide a better recovery from anesthesia than other drugs [1] The main side effect of propofol is hypotension $[1,2]$, but other more important side effects have been reported, such as pancreatitis [3], transient desaturation and apnea [2], and acute hepatitis [4]. Liver injury secondary to the use of propofol has been associated with long-term infusion of the drug, rhabdomyolysis, acidemia and bradyarrythmias [4]. The pathophysiology of propofol-induced hepatitis remains unclear. Some authors point to a immunologic mechanism as the cause of liver injury associated with the use of another sedative agent, pethidine [5]. In spite of these side effects, we consider that propofol remains the drug of choice for brief sedation in ERCP.

Endoscopy_UCTN_Code_CPL_1AK_2AC Endoscopy_UCTN_Code_CPL_1AK_2AJ
F. J. Polo-Romero, P. Paricio, A. Tovar, J. M. Alonso Internal Medicine Service, Hospital Los Arcos, Murcia, Spain

\section{References}

1 Chen WX, Lin HJ, Zhang WF et al. Sedation and safety of propofol for therapeutic endoscopic retrograde cholangiopancreatography. Hepatobiliary Pancreat Dis Int 2005; 4: $437-440$

2 Jung M, Hofmann C, Kiesslich R, Brackrtz A. Improved sedation in diagnostic and therapeutic ERCP: propofol is an alternative to midazolam. Endoscopy 2000; 32: $233-238$

3 Leisure GS, O'Flaherty J, Green L, Jones D. Propofol and postoperative pancreatitis. Anesthesiology 1996; 84: 224-227

4 Anand K, Ramsay MA, Crippin JS. Hepatocellular injury following the administration of propofol. Anesthesiology 2001; 95: 1523 1524

5 Kluender CN, Klein R, Kohler B. Dramatic increase in bilirubin after ERCP-pethidine as a possible cause of drug-induced hepatitis. $\mathrm{Z}$ Gastroenterol 2003; 41: 1157 - 1160

Bibliography

DOI 10.1055/s-2007-966881

Endoscopy 2008; 40: E49

(c) Georg Thieme Verlag KG Stuttgart · New York · ISSN 0013-726X

\section{Corresponding author}

\section{F. J. Polo-Romero, MD}

Internal Medicine Service

Hospital Los Arcos

Plaza de La Molinera, 1 - 2E

30500 Molina de Segura

Murcia

Spain

Fax: +34-967-305019

fpolo1111@yahoo.es 